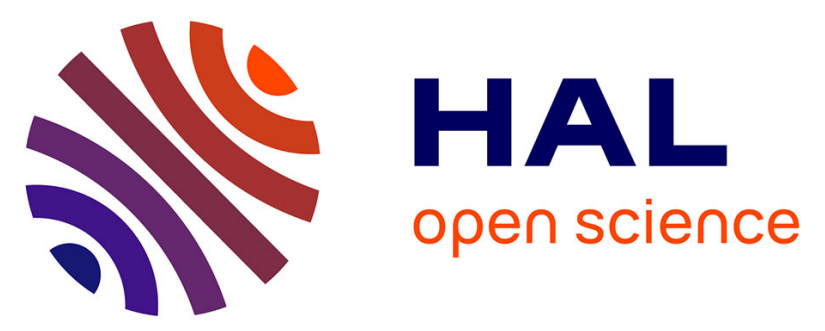

\title{
Comparison of X-ray and optical measurements in the near-field of an optically dense coaxial air-assisted atomizer
}

Julie K Bothell, Nathanaël Machicoane, Danyu Li, Timothy R. Morgan, Alberto Aliseda, Alan L Kastengren, Theodore J Heindel

\section{To cite this version:}

Julie K Bothell, Nathanaël Machicoane, Danyu Li, Timothy R. Morgan, Alberto Aliseda, et al.. Comparison of X-ray and optical measurements in the near-field of an optically dense coaxial air-assisted atomizer. International Journal of Multiphase Flow, 2020, 125, 10.1016/j.ijmultiphaseflow.2020.103219 . hal-02519242

\section{HAL Id: hal-02519242 \\ https://hal.science/hal-02519242}

Submitted on 26 Mar 2020

HAL is a multi-disciplinary open access archive for the deposit and dissemination of scientific research documents, whether they are published or not. The documents may come from teaching and research institutions in France or abroad, or from public or private research centers.
L'archive ouverte pluridisciplinaire HAL, est destinée au dépôt et à la diffusion de documents scientifiques de niveau recherche, publiés ou non, émanant des établissements d'enseignement et de recherche français ou étrangers, des laboratoires publics ou privés. 
Second revision for submission to: International Journal of Multiphase Flow

\title{
Comparison of X-ray and optical measurements in the near-field of an optically dense coaxial air-assisted atomizer
}

\author{
Julie K. Bothell ${ }^{\mathrm{a},}$, , Nathanael Machicoane ${ }^{\mathrm{b}}$, Danyu Li ${ }^{\mathrm{a}}$, Timothy B. Morgan ${ }^{\mathrm{a}}$, \\ Alberto Aliseda $^{\mathrm{b}}$, Alan L. Kastengren ${ }^{\mathrm{c}}$, Theodore J. Heindel ${ }^{\mathrm{a}}$ \\ ${ }^{a}$ Center for Multiphase Flow Research and Education, Department of \\ Mechanical Engineering, Iowa State University, Ames, IA, USA

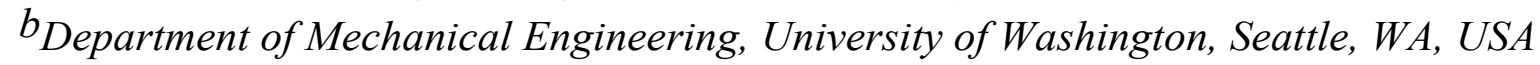 \\ ${ }^{c} X$-Ray Science Division, Advanced Photon Source, Argonne National Laboratory, \\ Lemont, IL, USA \\ *Corresponding author, jbothell@iastate.edu
}

\section{ABSTRACT}

Understanding the near-field region of a spray is integral to optimization and control efforts because this region is where liquid break-up and spray formation occurs, setting the conditions under which the spray dynamics evolve under the gas turbulence and droplet inertia. However, the high optical density of this region complicates measurements; thus, it is not yet well characterized. This paper is intended to compare four of the leading experimental techniques that are being used or developed to study the near-field region of a spray. These techniques are shadowgraphy, tube source X-ray radiography, high-speed synchrotron whitebeam X-ray imaging, and synchrotron focused-beam X-ray radiography. Each of these methods is applied to a canonical spray, using the same nozzle, under identical flow conditions. Synchrotron focused-beam radiography shows that a time-averaged Gaussian liquid distribution is a valid approximation very near the nozzle, before the core has broken apart. The Gaussian behavior continues as the spray progresses further downstream, showing self-similarity. A spray angle can be defined from the linear spreading of the Gaussian intensity distribution with downstream distance. The spray angle found from shadowgraphy is validated with focused-beam 
Second revision for submission to: International Journal of Multiphase Flow

27 testing. Additionally, a novel method of estimating the intact length of the spray from different

28 X-ray techniques, that uses broadband illumination, is presented.

29 Keywords: Near-field spray characterization, Shadowgraph, Spray diagnostics, Synchrotron X-

30 ray radiography, X-ray flow visualization

\section{Introduction}

Coaxial atomizers are of interest in research because of their use as fuel injectors for gas

34 turbines and engines, two-phase chemical reactors, and food processing (Lasheras

35 and Hopfinger, 2000). Spray droplet characterization has been a primary focus of this research,

36 especially in the combustion community (Aggarwal, 1998; Law, 1982). Some of the methods

37 commonly used to study the far-field region of sprays include Laser Doppler Velocimetry

38 (LDV), Phase Doppler Particle Analysis (PDPA), and Particle Image Velocimetry (PIV).

39 However, each of these methods relies on the spray being broken into droplets, and are thus not

40 applicable for studying the near-field region. The near-field region is where instabilities begin to

41 develop, and is of utmost importance because of its role in setting up the primary combustion

42 zone (Lightfoot et al., 2015). Fully characterizing this region is difficult because the thick liquid

43 core reflects most visible light, impeding the use of most noninvasive measurement methods.

44 Thus, the near-field region has not been studied with the depth and rigor that has been applied to 45 the mid- or far-field region.

46 Shadowgraphy and back-illuminated imaging are often used for studying sprays

47 (Castrejón-García et al., 2011; Stevenin et al., 2012; Westlye et al., 2017). These visible light

48 techniques are useful in making qualitative assessments about the spray and obtaining a measure

49 of the core length, but it is challenging to estimate accurately other quantitative measurements, 
such as spray angle. X-ray diagnostics have emerged recently as an alternative to optical

51 diagnostics for studying the near-field region (Heindel, 2018; Linne, 2013). Unlike visible light,

$52 \mathrm{X}$-rays are able to penetrate the dense liquid region, and their attenuation is related to the path

53 length and density of the materials through which they pass. The attenuation can then be used to

54 measure (or estimate if the attenuation is from a broadband source) the quantity of liquid present

55 in the line of sight along the X-ray beam. An additional advantage of X-rays is the mild

56 refraction and diffraction at liquid-gas interfaces, which enhances visualization (Kastengren et

57 al., 2012). Ballistic imaging is another measurement technique that has been used to investigate

58 the spray near-field (Linne et al., 2009), but is not covered in this study.

To understand how the data from these measurement techniques compare, this study uses

60 an identical experimental setup and flow conditions to provide a side-by-side comparison of

61 multiple techniques. The four techniques used in this study are shadowgraphy (as the visible

62 light technique), tube source X-ray radiography, synchrotron white-beam phase-contrast

63 imaging, and synchrotron focused-beam radiography. Core length and spray angle are the two

64 major defining parameters of the spray near-field that are compared. An accurate measure for the

65 core length was found from shadowgraphy and a method that uses X-ray techniques to estimate

66 this length was developed. The spray angle was found from focused-beam radiography, and the

67 spray angles from the other three methods were compared to this measurement. Additionally, the

68 capabilities, advantages, and disadvantages of each technique are discussed. A complementary

69 study using an impinging jet spray and structured light and 3-D X-ray CT reconstruction was

70 completed by Halls et al. (2013). Using the same impinging jet spray setup, Halls et al. (2014)

71 compared 2-D and 3-D mass distribution measures to focused-beam measurements. 
Second revision for submission to: International Journal of Multiphase Flow

\section{2. Experimental setup}

\section{$74 \quad 2.1$ Nozzle and Flow Conditions}

75 The nozzle used in these experiments, shown in Fig. 1, is a canonical two-fluid coaxial

76 atomizer (Machicoane et al, 2019). The liquid Reynolds number is defined by:

$$
\operatorname{Re}_{1}=\left(\mathrm{U}_{1} \mathrm{~d}_{1}\right) / v_{1}
$$

78 where $d_{1}=2.1 \mathrm{~mm}$ is the inner diameter of the liquid nozzle, $v_{1}$ is the kinematic viscosity of the

79 liquid, and $\mathrm{U}_{1}$ is the liquid mean exit velocity, calculated as $\mathrm{U}_{1}=\mathrm{Q}_{1} / \mathrm{A}_{1}$ where $\mathrm{Q}_{1}$ is the liquid flow

80 rate and $A_{1}$ is the exit area of the liquid nozzle. With $d_{1}=2.1 \mathrm{~mm}$ and a liquid nozzle length of

$81110 \mathrm{~mm}$, the length to diameter ratio is 52 ensuring a fully developed flow. The inner diameter of

82 the gas nozzle at the exit is $d_{g}=10 \mathrm{~mm}$, and the gas Reynolds number is defined by:

$$
\operatorname{Re}_{\mathrm{g}}=4 \mathrm{Q}_{\mathrm{tot}} /\left(\pi \mathrm{d}_{\mathrm{eff}} v_{\mathrm{g}}\right)
$$

84 where $\mathrm{Q}_{\text {tot }}$ is the total gas flow rate, and $v_{\mathrm{g}}$ is the kinematic viscosity of air. The effective inner

85 diameter of the gas nozzle ( $\left.\mathrm{d}_{\mathrm{eff}}\right)$ is defined as:

$$
\mathrm{d}_{\text {eff }}=\left(\mathrm{dg}_{\mathrm{g}}{ }^{2}-\mathrm{Dl}^{2}\right)^{1 / 2}
$$

87 which is the diameter of a circle with the same exit area as the gas nozzle, and $\mathrm{D}_{1}=2.7 \mathrm{~mm}$ is the

88 outer diameter of the liquid nozzle. The total gas flow rate is composed of straight and swirl air.

89 As shown in Figure 1, straight air enters the gas plenum directed at the liquid needle centerline

90 whereas swirl air enters the gas plenum tangent to the plenum wall (which is not used in the

91 current study).

92 

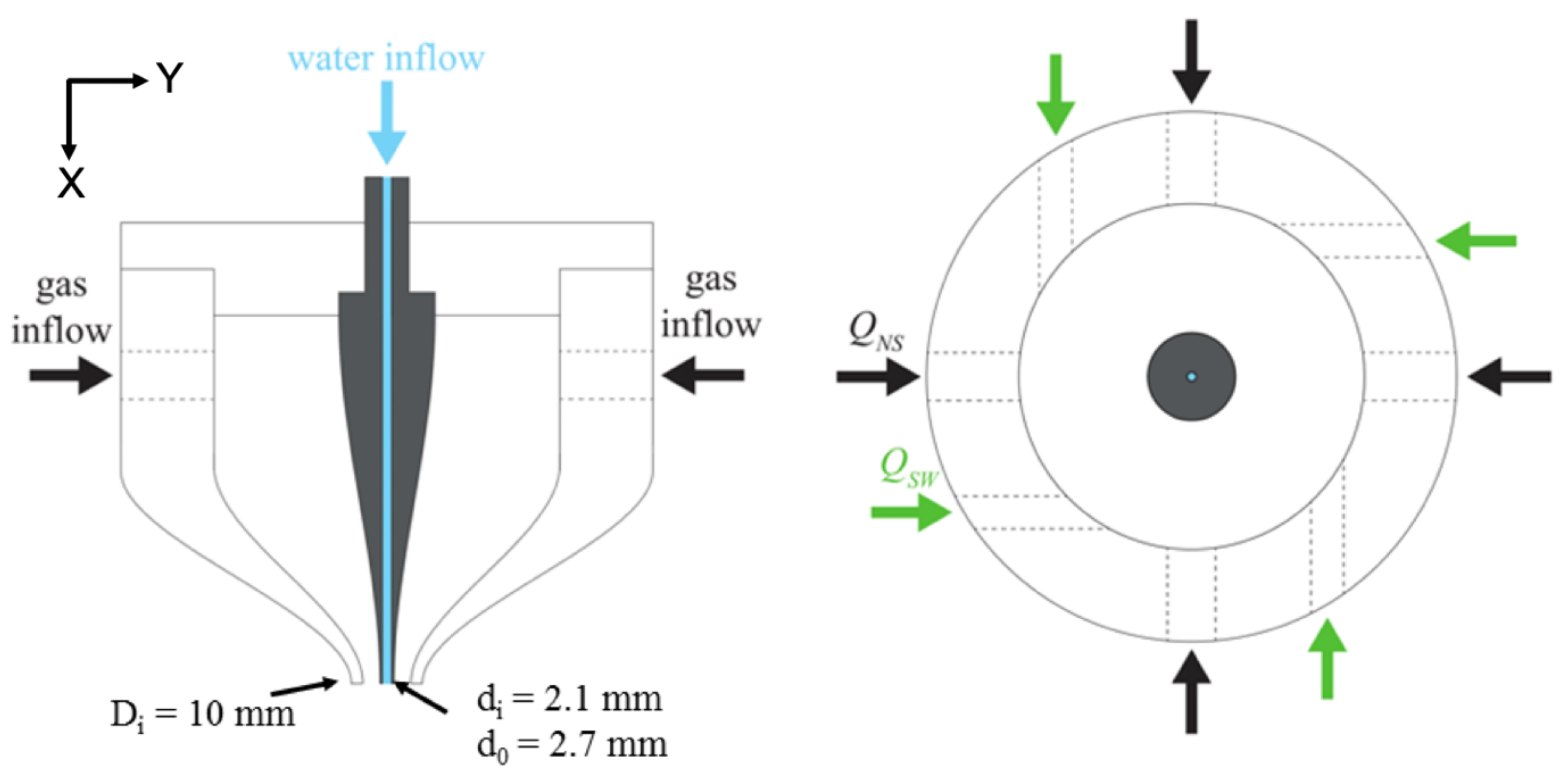

Figure 1: Nozzle schematic showing liquid and gas inlets of a two-fluid coaxial nozzle. QNS shows the locations for straight air flow and Qsw shows how swirl air is added (this functionality is not utilized in the current study).

The momentum flux ratio $(\mathrm{M})$ is defined by:

$$
\mathrm{M}=\left(\rho_{\mathrm{g}} \mathrm{Ug}_{\mathrm{g}}^{2}\right) /\left(\rho_{\mathrm{l}} \mathrm{U}_{1}^{2}\right)
$$

where the subscripts $g$ and 1 define the gas and liquid properties, respectively, and $\rho$ is the fluid density. Additionally, the Weber number (We) and mass loading ratio (m) are defined by:

$$
\mathrm{m}=\left(\rho_{1} \mathrm{U}_{1} \mathrm{~A}_{\mathrm{l}}\right) /\left(\rho_{\mathrm{g}} \mathrm{U}_{\mathrm{g}} \mathrm{A}_{\mathrm{g}}\right)
$$

where $\sigma$ is the interfacial tension.

All length scales have been nondimensionalized with $\mathrm{d}_{1}$ where appropriate; hence $\mathrm{Y}=\mathrm{y} / \mathrm{d}_{1}$ is the spanwise coordinate and $\mathrm{X}=\mathrm{x} / \mathrm{d}_{1}$ is the axial coordinate originating at the nozzle

107 exit. The liquid flow rate is constant for all test conditions considered in this study, yielding a

108 fixed Reynolds number of $\mathrm{Re}_{1}=1,100$ to ensure laminar flow, with a large We and small $\mathrm{m}$ to 
Second revision for submission to: International Journal of Multiphase Flow

109 ensure that the breakup and interfacial instabilities are driven by the gas (Lasheras et al., 1998;

110 Lasheras and Hopfinger, 2000). The gas flow conditions selected for this study are summarized

111 in Table 1.

112

113 Table 1: Gas Reynolds number, momentum flux ratio, Weber number, and mass loading for each condition used in this study.

\begin{tabular}{|c|c|c|c|}
\hline $\mathbf{R e}_{\mathbf{g}}$ & $\mathbf{M}$ & $\mathbf{W e}$ & $\mathbf{m}$ \\
\hline 21,200 & 6.0 & 40.3 & 0.55 \\
\hline 31,100 & 12.9 & 86.8 & 0.37 \\
\hline 46,500 & 28.9 & 194.1 & 0.25 \\
\hline 69,300 & 64.1 & 430.5 & 0.17 \\
\hline
\end{tabular}

115

116 2.2 Shadowgraphy

High-speed back-illuminated imaging and shadowgraphy have been widely used for

118 studying sprays because the interfaces between the liquid and gas regions are easily visible

119 (Castrejón-García et al., 2011; Stevenin et al., 2012; Westlye et al., 2017). The images generally

120 show the entire region of interest of the spray at a high temporal resolution, which enables

121 spatiotemporal analysis of the data. However, it is not possible to capture internal details of the

122 spray. Additionally, dense clouds of droplets obscure the light, so they cannot be distinguished

123 from patches of liquid.

124 Shadowgraphy experiments in this study were conducted using a red light emitting diode

125 (LED) panel, schematically shown in Fig. 2. Although the light coming from this source was not

126 truly parallel, as it would be in shadowgraphy, it has less than 5 degrees divergence so it was

127 considered parallel with negligible error, for simplification in the analysis. As light passes

128 through the spray, it is reflected, refracted, and diffracted away from its original path wherever

129 liquid is present; this creates a shadow in the resulting image. Using a visible light source makes 
130 shadowgraphy subject to multiple scattering, also shown in Fig. 2, where the light reflects and

131 diffracts off of multiple droplets, decreasing the sharpness and contrast of the resulting image.

132 The high curvature of droplets also tends to act as a lens, focusing light to the center of the

133 shadow, which results in a bright spot in the center of larger droplets.

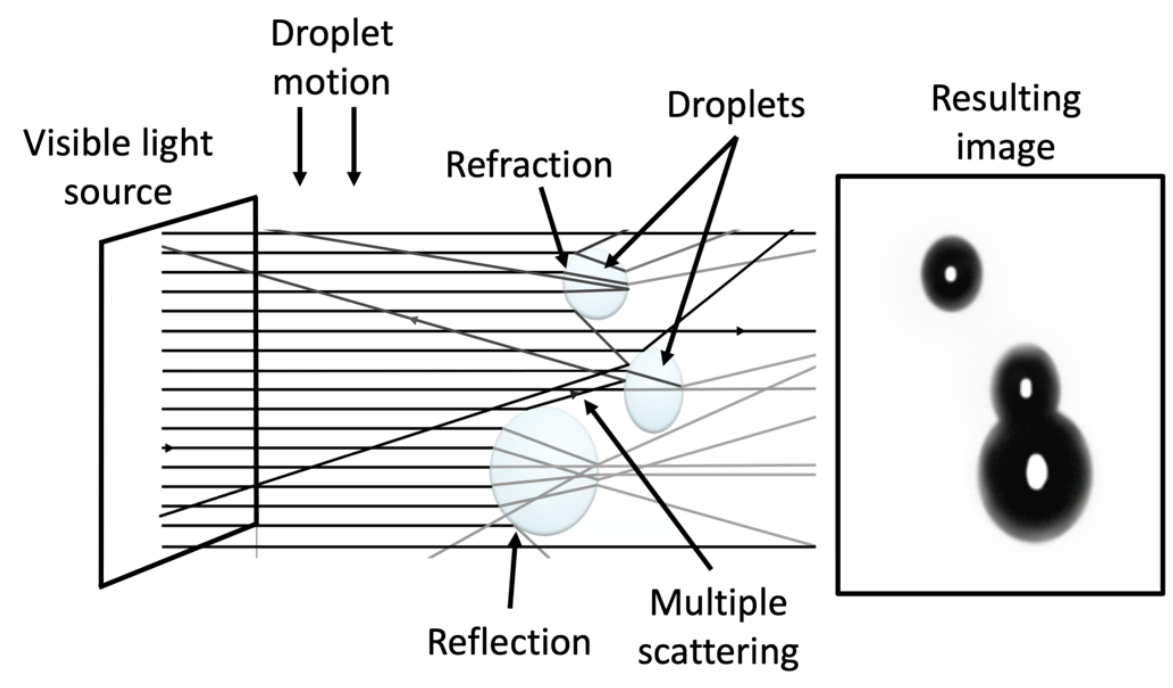

136 Figure 2: Shadowgraphy: High-speed imaging using visible light to capture a still shadow of a spray (schematic not to scale).

\section{$2.3 X$-ray Imaging}

Another current method of imaging sprays uses X-rays rather than visible light (Heindel,

141 2018). The primary advantage of this type of measurement is that the X-rays attenuate (but not

142 reflect and barely refract) as they pass through liquid, greatly reducing refraction and multiple

143 scattering. The resulting images provide internal details of the spray. This study compares the

144 images taken from two types of X-ray producing devices, a tube source and a synchrotron. The

145 two are considered independently because of the difference in how they produce X-rays and the 
Second revision for submission to: International Journal of Multiphase Flow

146 large disparity in the radiation intensity the sources produce, which leads to different types of

147 X-ray measurements.

$148 \quad$ 2.3.1 Tube Source X-rays

149 Tube source X-rays are produced when electrons are accelerated with a high voltage

150 electric field in a cathode ray tube where the electrons impact a metal target (anode) which

151 decelerates the electrons, emitting radiation in the X-ray spectrum. Figure 3 schematically shows

152 the tube source X-ray setup used in current experiments at Iowa State University's X-ray Flow

153 Visualization Laboratory, which has been described in detail elsewhere (Heindel et al., 2008).

154 The X-ray source has a cone-shaped beam and contains a wide range of photon energies, referred

155 to as broadband X-rays or white-beam X-rays. As the beam propagates through the spray, a

156 fraction of the photons are absorbed by the liquid so that the beam intensity decreases; the

157 decrease is a function of the fluid medium, the amount (path length) of fluid, and the X-ray

158 photon energy. Rather than using the equivalent path length (EPL) of the spray, calculations

159 from tube source radiography use the optical depth values directly which are equivalent to

$160 \mu^{*} \mathrm{EPL}$, where $\mu$ is the X-ray attenuation coefficient ( $\mathrm{Li}$ et al., 2019). Note that $\mu$ is a function of

161 the material through which the X-rays pass, as well as the wavelength of the X-ray energy, and is

162 typically tabulated for monochromatic X-ray sources, but is a complicated function for

163 polychromatic X-ray sources common in tube sources. The relatively low intensity of the tube

164 source used in this study requires an exposure time of $20 \mathrm{~ms}$, and acquisition speeds of the order

165 of 10 FPS, which are too slow to capture fast-moving events, so the resulting images become

166 blurred. The blurring makes it difficult to interpret individual images, but these can be time-

167 averaged for mean spray measurements. Additionally, the tube source has a relatively large focal

168 spot, which results in a non-negligible penumbra effect (caused by X-rays hitting the same spot 
Second revision for submission to: International Journal of Multiphase Flow

169 on an occluding object from different angles), causing blurred edges. One advantage of the tube

170 source is the larger X-ray beam, which allows the entire spray region to fit inside the beam at one

171 time. The field of view for radiographs in this study was $22.5 \times 26 \mathrm{~mm}$, the tube voltage was

$17250 \mathrm{keV}$, and the current was $2.0 \mathrm{~mA}$. More details about the tube source X-ray setup can be

173 found in Heindel et al. (2008) or the setup of Li et al. (2018).

174

175

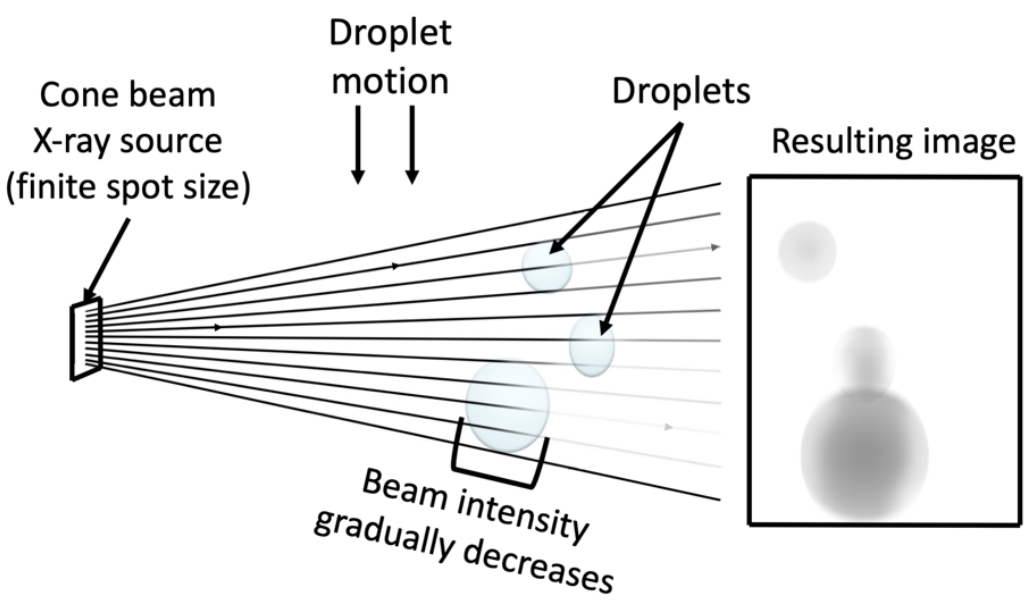

176 Figure 3: Tube source radiography: The X-ray beam projects at a cone angle and the intensity decreases in the presence of liquid. The resulting image can be correlated to local projected mass distribution (figure not to scale).

\subsubsection{Synchrotron X-rays}

The synchrotron beamline used for the measurements in this study was the 7-BM

182 beamline at the Advanced Photon Source at Argonne National Lab; the setup is detailed

183 elsewhere (Kastengren et al., 2012; Heindel, 2018). The synchrotron source provides extremely

184 intense X-rays with an energy range of 5.1-12 keV that are created by fast-moving electrons

185 when they are steered by bending magnets or undulators. Using this X-ray source for 
Second revision for submission to: International Journal of Multiphase Flow

186 radiography of sprays is advantageous because the high X-ray intensity enables microsecond

187 exposures and kilohertz frame rates. This permits the acquisition of time-resolved measurements

188 or images, which allows for the capture of dynamic events and minimizes motion blur. The beam

189 is also highly collimated, which minimizes the penumbra effect, and increases the phase-contrast

190 effect.

$191 \quad$ 2.3.2.1 Synchrotron white-beam imaging

192 White-beam phase-contrast imaging is named because the beam is not a single

193 wavelength but, instead, uses the broadband emission from the X-ray source. The phase-contrast

194 effect is caused by refraction and Fresnel diffraction where a relatively large propagation

195 distance increases the intensity of phase boundaries. The white-beam phase-contrast X-ray setup

196 is shown in Fig. 4. The beam is highly collimated and the source is approximately $35 \mathrm{~m}$ from the

197 test section. The maximum beam size is approximately $6 \times 8 \mathrm{~mm}$. As the beam propagates

198 through the spray, the intensity decreases. This concept is shown for the droplets in Fig. 4 as

199 each of the lines, representing a section of the beam, decreases in intensity depending on the path

200 length of liquid through which it passes. After going through the spray, the beam illuminates a

201 scintillator (not pictured), which creates a visible light image proportional to the incident X-ray

202 intensity. The visible light image is then reflected off a mirror and captured by a high-speed

203 camera. Additional details of white-beam phase-contrast imaging are presented by Heindel

204 (2018).

205 
Second revision for submission to: International Journal of Multiphase Flow

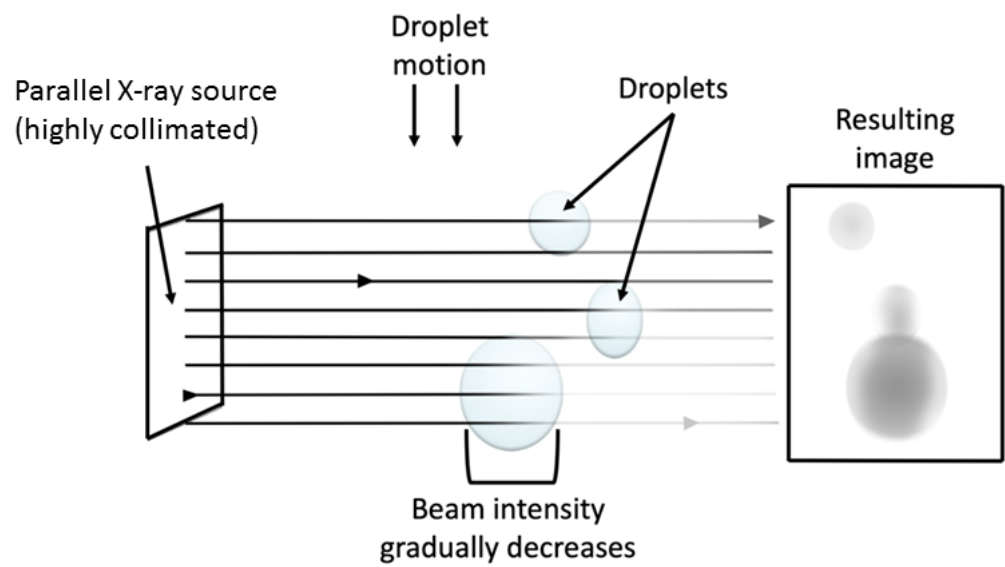

207 Figure 4: Synchrotron X-ray imaging: The nearly parallel X-ray beams pass through a spray where the intensity decreases, dependent on the amount of liquid through which they pass. In actual images, the edges are enhanced by a bright region around the droplets (phase-contrast effect, not shown in this figure). The resulting image can be correlated to the local projected mass distribution (figure not to scale).

\subsubsection{Synchrotron focused-beam radiography}

214 Focused-beam radiography in this study was performed by first filtering the white-beam

215 into a monochromatic beam, and then focusing the beam into a small cross-sectional area of

$2165 \times 6 \mu \mathrm{m}$ at $8 \mathrm{keV}$. The resulting beam was then raster-scanned across the spray to acquire line-

217 of-sight measurements. For focused-beam radiography, as the beam passes through the spray, it

218 reduces in intensity in the same way as white-beam imaging. After passing through the spray, the

219 X-ray beam illuminates a PIN diode that produces a voltage, proportional to the beam intensity,

220 which is then recorded. By scanning across the spray, intensity as a function of time signals are

221 recorded at multiple locations. Focused-beam radiography can be highly time-resolved. In this

222 study, focused-beam radiographs are taken at an effective frequency of $270 \mathrm{kHz}$ for $10 \mathrm{sec}$. at

223 each line-of-sight location in the spray. 
Second revision for submission to: International Journal of Multiphase Flow

Because this setup requires the beam to be focused to a small cross-sectional area, the full

225 power of the beam is not required, which enables the use of a nearly monochromatic X-ray

226 beam. This greatly simplifies the subsequent analysis, since X-ray absorption is strongly

227 dependent on X-ray wavelength. A monochromatic beam eliminates beam hardening

228 (preferential absorption of lower energy radiation) so that Beer-Lambert's Law provides an

229 accurate measure of the EPL:

$$
\mathrm{EPL}=(1 / \mu) \ln \left(\mathrm{I}_{0} / \mathrm{I}\right)
$$

231 where $\mathrm{I}_{0}$ is the incident beam intensity, $\mathrm{I}$ is the beam intensity after passing through the spray,

232 and $\mu$ is the $\mathrm{X}$-ray attenuation coefficient. By knowing the X-ray photon energy, the attenuation

233 coefficient can be obtained from the NIST XCOM database (Berger et al., 2010) which is then

234 used to obtain the equivalent path length (EPL). Being able to compute the instantaneous EPL of

235 the liquid makes it possible to measure the mass distribution of the spray, as well as for

236 additional spray dynamic properties to be computed.

237 The setup for focused-beam radiography is shown in Fig. 5. The inset of the figure shows 238 a representative measured beam intensity over time, changing as the droplets pass through the

239 probe volume. A spherical droplet yields an elliptical curve whose minimum corresponds to its

240 diameter when it is intersected at its center. Droplets that are in the same line of sight result in

241 the superposition of multiple droplets in the measurement, giving more complex results and 242 making it difficult to distinguish the signal from each droplet. 


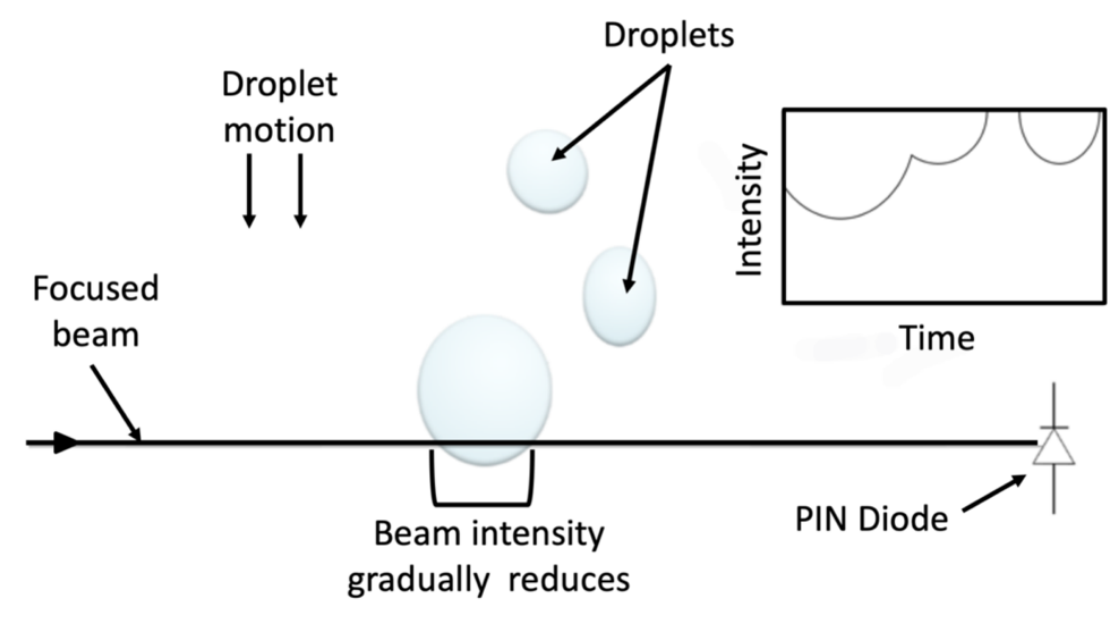

245 Figure 5: Focused-beam radiography: Intensity of an X-ray beam, that has been focused down to a small cross-sectional area, decreases following Beer-Lambert's Law as it passes through liquid (figure not to scale).

\section{Results}

\subsection{Shadowgraphy}

251 A shadowgraph image of the spray is shown in Fig. 6 where many of the visible spray

252 characteristics are identifiable. The liquid core is nearest to the nozzle and characterized as a

253 continuous section of thick liquid that has not yet broken apart. Primary breakup can be seen,

254 leading to the formation of ligaments and liquid sheets. As ligaments move further downstream,

255 they break up into large droplets while liquid sheets break into smaller droplets. Once the

256 primary breakup process is finished and the liquid moves to the mid-field region, the spray has

257 become more dilute and broken into droplets that continue to split apart as the turbulent gas flow

258 advects them downstream. When using shadowgraphy, large particles can be seen, but their

259 smaller neighbors often go unobserved because of the low contrast at that scale and the

260 insufficient spatial resolution. Additionally, a percentage of smaller droplets is not captured 
261 when the light source is not perfectly parallel. The minimum resolvable object size measured for

262 this setup was $0.25 \mathrm{~mm}$.

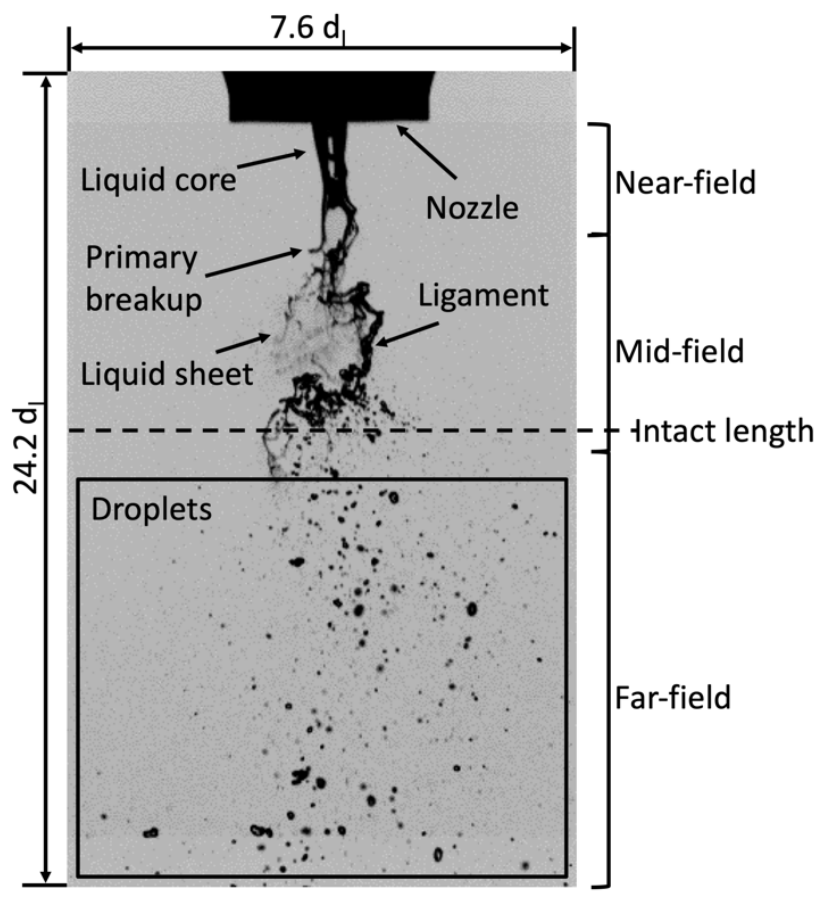

264 Figure 6: Instantaneous shadowgraph image from a high-speed spray sequence, taken at $\mathrm{Re}_{\mathrm{l}}=1,100$ and $\mathrm{Re}_{\mathrm{g}}=21,200$ with a frame rate of $10 \mathrm{kHz}$ and exposure time of $1 \mu \mathrm{s}$.

268 liquid was dark, image thresholding was used to create a binary image that defined the gas-liquid 269 interface. However, the center region of the liquid droplets and the liquid jet core were lighter or 270 the same intensity as the background because the liquid acted as a lens and focused the

271 illumination; this was corrected through image processing when binarizing the images. A global, 272 bimodal threshold that minimized the weighted within-class variance was applied to all images, 273 which provided binary images with minimized thresholding error. After identifying the location 274 of the liquid, the intact length (longitudinal extent of the instanteous section of liquid still fully 
Second revision for submission to: International Journal of Multiphase Flow

275 attached to the nozzle) from each image was averaged together. The error in intact length

276 measurements from shadowgraphy images was calculated to be $15 \%$ by Charalampous et al.

277 (2016) for a spray with a more dense droplet field, so the experiments here are estimated to have

278 at or below 15\% measurement error. The average intact length as determined by shadowgraphy

279 for varying flow rates will be compared to other methods below.

$280 \quad 3.2$ Tube Source X-rays

281 A time-average tube source X-ray radiograph, representative of the images taken for this

282 study, is shown in Fig. 7. The canonical nozzle is the bright region along the top of the image,

283 and the image has been normalized to emphasize the spray region, which appears as the dark

284 region. The spray in the original tube source radiograph is close to a time-average image because

285 the exposure time of $20 \mathrm{~ms}$ long compared to flowfield time scales. The darker regions represent

286 a longer liquid pathlength, and the lighter regions represent less attenuation by the liquid. To

287 increase the contrast between the liquid and the gas background, the liquid was doped with

288 potassium iodide $(\mathrm{KI})$ at a concentration of $20 \%$ by mass, which provides measurements with an

289 estimated measurement error of 5\%. Past studies have shown that a KI concentration of up to

$29020 \%$ has a negligible effect on the density and viscosity of water, and a KI concentration of $20 \%$

291 by mass does not affect beam hardening (Halls et al., 2014). The image shown in Fig. 7, at a

292 resolution of $327 \times 377$ pixels, covers an area that is $10.7 \times 12.4 \mathrm{~d}_{1}(22.5 \times 26 \mathrm{~mm})$, and is from a

293 video sequence that was acquired at a rate of 10 FPS using a Photron FastCAM Mini AX50. 
Second revision for submission to: International Journal of Multiphase Flow

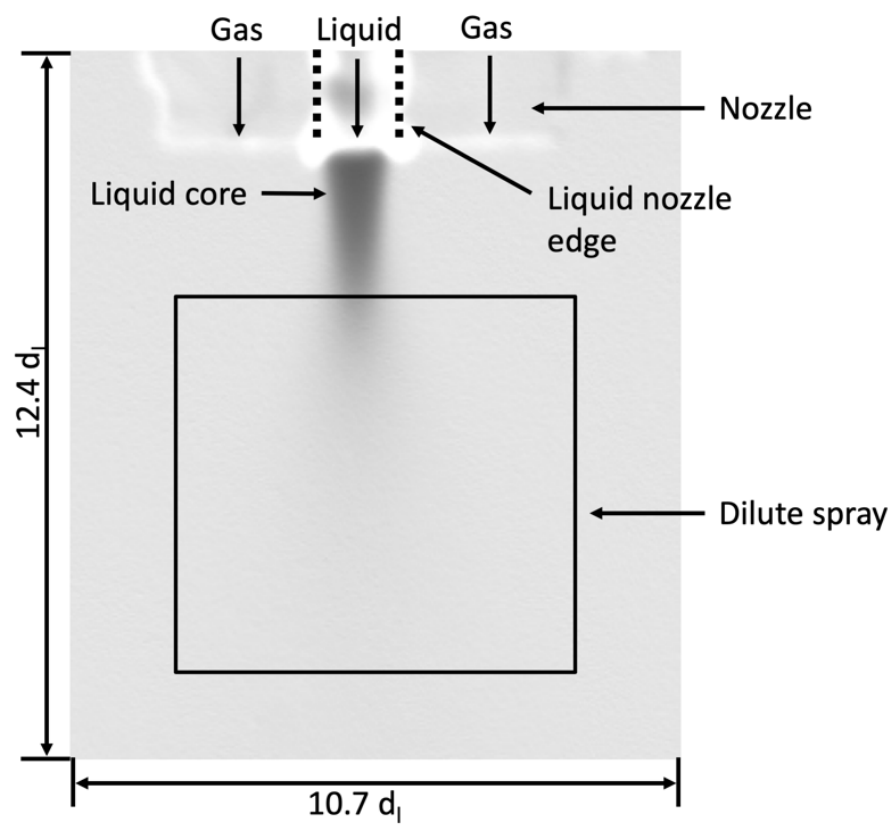

296 Figure 7: Tube source X-ray radiograph. Single radiograph normalized to emphasize the spray region showing the liquid mass distribution for the entire flow field region of interest. The momentum flux ratio was 6.0 with an image capture rate of 10 FPS. Gas and liquid conditions are $\mathrm{Re}_{\mathrm{l}}=1,100$ and $\mathrm{Re}_{\mathrm{g}}=21,200$. over several seconds, to get a mean picture of the spray attenuation. The optical depth is used in

303 these measurements because the X-ray attenuation coefficient is not precisely known for the

304 broadband tube source (Li et al., 2019).

\subsection{Synchrotron White-Beam Imaging}

Figure 8 shows several synchrotron white-beam images from locations along or near the

307 centerline of the spray. Each image has an exposure time of $1.05 \mu$ s and was taken from a series

308 of X-ray images that were captured at a rate of $6 \mathrm{kHz}$ with a Photron FastCAM Mini AX50. The

309 images were taken at different locations along the spray, as the beam size is much smaller than 
310 the width of the spray; thus, they could not be taken synchronously. This highlights a notable

311 difference with the tube source X-ray imaging used in this study. The tube source was able to

312 image the spray in its entirety, but at a slower frame rate and lower flux, whereas the synchrotron

313 white-beam imaging provided high-speed high-resolution images but over a smaller field of

314 view. The synchrotron beam was setup for phase-contrast imaging in this study, which enhances

315 the edges of phase differences, making the liquid-gas interface more clearly delineated.

316 However, the analysis presented below does not use the phase-contrast effect, but rather treats

317 the technique as attenuation only imaging.

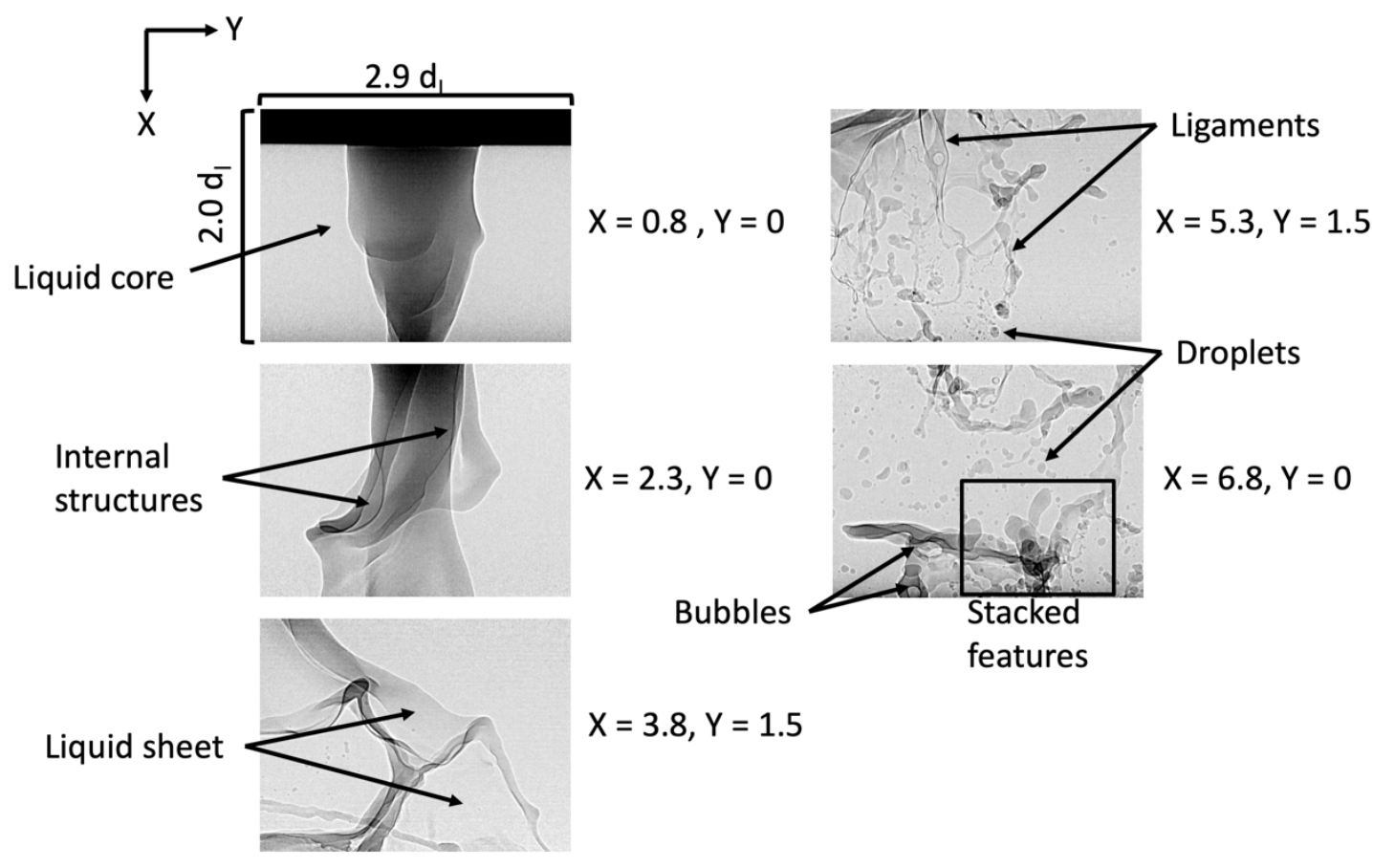

320 Figure 8: Synchrotron white-beam X-ray images were taken near, or along the centerline $(\mathrm{Y}=0)$ while the $\mathrm{X}$ distance increases with $\mathrm{X}=0$ corresponding to the jet exit. $\mathrm{X}$ and Y locations were non-dimensionalized by $\mathrm{d}_{1}$, and identify the image center. $\mathrm{Re}_{\mathrm{l}}=1,100$ and $\mathrm{Re}_{\mathrm{g}}=21,200$ with a capture rate of $6 \mathrm{kHz}$ and an exposure time of $1.05 \mu \mathrm{s}$ 
Second revision for submission to: International Journal of Multiphase Flow

Unique spray characteristics are distinguished in each image. Unlike shadowgraphy that

327 mostly shows a binary representation of the liquid location, synchrotron X-ray imaging measures

328 the optical depth, which is related to the amount of liquid that is present in the projected image.

329 Hence, the ability to do high-speed X-ray imaging provides more details and highlights many

330 spray features that are not observed with other imaging methods, such as overlapping droplets

331 and liquid features. The liquid core in the spray shown here was more complex than a simple jet

332 with bag formation, as shown in Fig. 6 with shadowgraphy. The phase-contrast image at the

333 nozzle exit $(\mathrm{X}=0.8, \mathrm{Y}=0)$ shows the initial formation of bags and ligaments, even before one

334 nozzle diameter away from the nozzle exit plane. Moving downstream $(X=2.3, Y=0)$, internal

335 structures of the core continue to be seen as bags start to form. Then, the spray begins to form

336 thin liquid sheets and ligaments $(\mathrm{X}=3.8, \mathrm{Y}=1.5)$ which break apart as they advect downstream

337 to form small and large droplets, respectively. One particular challenge with high-speed X-ray

338 imaging is that specific flow features are all imaged in the same projection, shown as "stacked

339 features" in Figure $8(\mathrm{X}=6.8, \mathrm{Y}=0)$. However, one example of the unique features of this

340 imaging method is the ability to capture air bubbles within the liquid region $(\mathrm{X}=6.8, \mathrm{Y}=0)$.

3413.4 Synchrotron Focused-Beam Radiography

342 Synchrotron focused-beam radiography provides an X-ray intensity measurement as a

343 function of time. In this study, an effective signal acquisition rate of $270 \mathrm{kHz}$ over a $10 \mathrm{sec}$.

344 period was recorded at each raster scan location. The instantaneous intensity signal is then used

345 with Beer-Lambert's Law (Eq. (7)) to determine the instantaneous equivalent path length (EPL).

346 Averages at each location were used to obtain contour maps of the spray over the entire flow

347 field. Because data were taken at discrete locations, the data were linearly interpolated to 
Second revision for submission to: International Journal of Multiphase Flow

348 estimate the EPL values between acquisition locations. For the given flow conditions, the

349 maximum EPL was larger than the inner diameter of the liquid nozzle, showing that the liquid

350 spreads out slightly after leaving the nozzle, wetting the outer liquid needle surface, so the initial

351 jet diameter is approximately equal to the outer needle diameter, but still remains intact. This is

352 confirmed by images from synchrotron white-beam phase-contrast imaging (Li et al., 2017).

353 Using the same method as Kastengren et al. (2008), the absorption coefficient in Beer-Lambert's

354 law has an uncertainty of approximately $1.5 \%$, and the measurement positions have an axial

355 uncertainty of $\pm 20 \mu \mathrm{m}$ and a spanwise uncertainty of $\pm 5 \mu \mathrm{m}$. The total measurement uncertainty

356 is therefore estimated to be $\pm 3.2 \%$.

357 A sample of the instantaneous EPL from focused-beam data at $(\mathrm{X}, \mathrm{Y})=(2.38,-0.48)$

358 from a short time span $(1.6 \mathrm{~ms})$ is shown in Fig. 9a. These data were acquired by raster scanning

359 across the spray and pausing at each data point location for 10 seconds to collect data, which was

360 long enough to gather good statistical data for the time-varying system. From plots like these, the

361 times when there was no liquid present are evident because the equivalent path length is very

362 near zero. Individual droplets passing through the focused-beam are easily identified by elliptical

363 curves in EPL. For much of the signal, however, the precise spray dynamics are difficult to

364 discern because the signal is composed of several overlapping projected liquid dynamics; one of

365 these regions is identified in Figure 9a as overlapping spray dynamics. 
Second revision for submission to: International Journal of Multiphase Flow

(a)

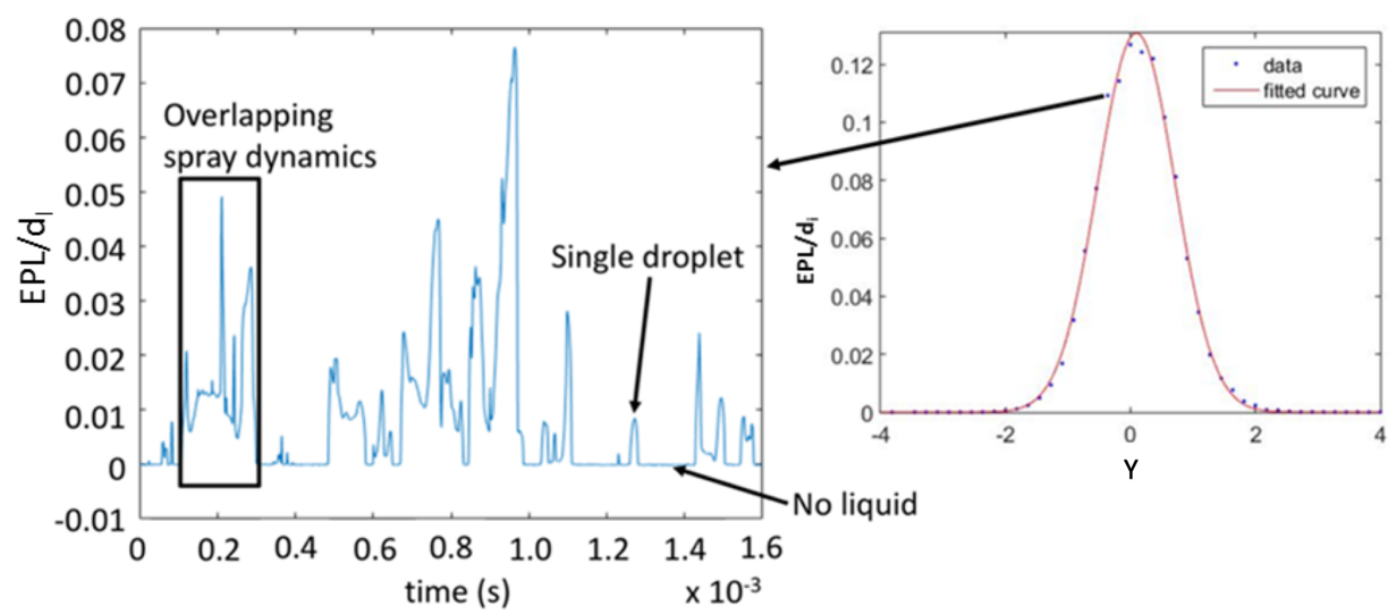

(b)
367 tested with data that were taken $1 d_{1}$ or farther from the nozzle exit plane. To visualize the self383 similarity of the data, the EPL was scaled so that:

Figure 9: Focused-beam PIN diode signal, with $\mathrm{Re}_{1}=1,100$ and $\mathrm{Re}_{\mathrm{g}}=21,200$ : (a) a short sample of focused-beam data showing the instantaneous effective path length as a function of time, taken at $\mathrm{X}=2.38$ and $\mathrm{Y}=-0.48$ and $(\mathrm{b})$ the average $E P L / \mathrm{d}_{1}$ from one scan across the spray at $\mathrm{X}=2.38$.

\subsection{Self-Similarity}

To determine if the spray angle can be accurately described as the angle between two straight lines, it was first necessary to determine if the spray was self-similar and widening in a linear fashion. It has been established that the quantity of liquid present in the cross-sectional area of a spray field can be described by a self-similar Gaussian curve in the mid-field region (Powell et al., 2000; Yue et al., 2001). The Gaussian distribution follows the velocity in singlephase jets (Van Wissen et al., 2004).

Using focused-beam raster scans that span the width of the spray, a Gaussian curve fit accurately represented the EPL data in the span-wise direction for all cases of the spray that were 
Second revision for submission to: International Journal of Multiphase Flow

$$
\mathrm{EPL}_{\text {scaled }}=\mathrm{EPL}(\mathrm{x}, \mathrm{y}) / \mathrm{EPL}(\mathrm{x})_{\max }
$$

385 where EPL(x) $\max$ was the maximum EPL at each axial (x) location. Additionally, the EPL

386 distributions were scaled for the spray width using the Y location corresponding to $2 \sigma$ where $\sigma$ is

387 the standard deviation, so that $\mathrm{y}_{\text {scaled }}=\mathrm{y} /\left.\mathrm{y}\right|_{2 \sigma}$. This scaling collapsed all the data, proving self-

388 similarity. A sample of the scaled data for $\operatorname{Re}_{\mathrm{l}}=1,100$ and $\mathrm{Re}_{\mathrm{g}}=21,200$ is shown in Fig. 10a.

(a)

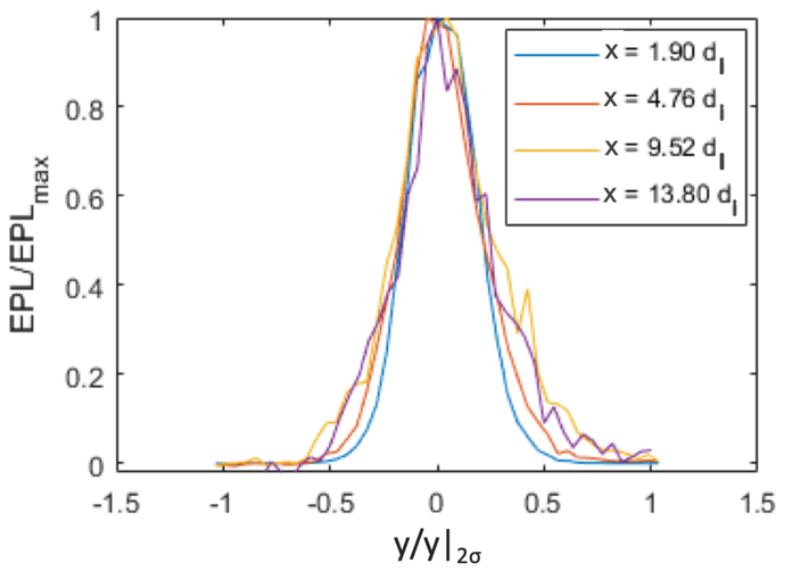

(b)

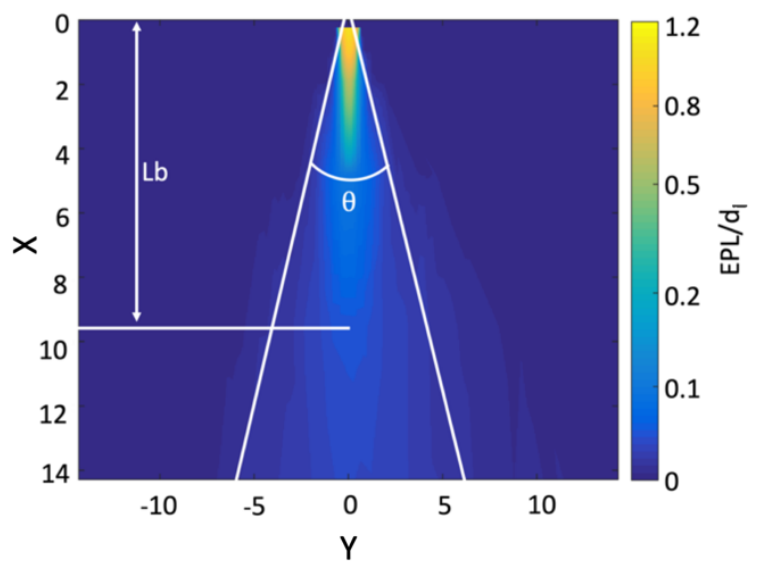

390

Figure 10: $\mathrm{Re}_{\mathrm{g}}=1,100$ and $\mathrm{Re}_{1}=21,200$, showing (a) self-similar jet profiles, scaled by EPL $\max$ and $2 \sigma$, and (b) average EPL/d $\mathrm{d}_{1}$ contour map showing the jet spreading angle, $\theta$, and the intact length, $\mathrm{L}_{\mathrm{b}}$.

\subsection{Spray Angle Comparison}

The results from focused-beam radiography, shadowgraphy, and tube source radiography were all used to create a time-averaged spray map. For focused-beam radiography, the average spray map represented the average EPL, as shown in Figure 10b. For shadowgraphy, the average spray map was an average of binarized images representing the probability of the presence of liquid. For tube source X-rays, the average spray map represented the averaged intensity which is 
Second revision for submission to: International Journal of Multiphase Flow

401 linked to the optical depth, and was created after individual images were normalized with the 402 background intensity, shown in Figure 7. The phase-contrast imaging presented here does not 403 provide sufficient information to calculate the spread angle because the phase-contrast imaging 404 region did not capture the entire spray. Stitching phase-contrast images together was not possible 405 because the incident X-ray flux from the synchrotron varied with time, producing non-uniform 406 background intensities from one imaging region to another. The period of the X-ray flux 407 variance ranged from milliseconds to several hours and developing a method of adjusting images 408 based on the flux variance was beyond the scope of this study.

409 At any given axial location, a Gaussian curve fit was applied to the data and the y410 location of $2 \sigma$ from the Gaussian curve was defined as the edge of the spray for this study. The 411 spray angle was then defined as the angle between the two lines that connect the $2 \sigma$ locations.

412 This angle is shown as $\theta$ for $M=6.0$ in Figure $10 \mathrm{~b}$. Using the $2 \sigma$ location as the spray edge is an

413 arbitrary choice, but is valid for comparison because the angle would scale with the Gaussian 414 distribution so that the spray angle for any $\sigma$ location could be calculated by multiplying the 415 current spray angle by a constant.

416 Comparing the spray angle obtained from shadowgraphy, focused-beam radiography, and 417 tube-source radiography gives different results for low gas momentum flux ratios. At higher gas 418 momentum flux ratios, the results are much closer for all three methods, as shown in Figure 11.

419 At low momentum flux ratios, as the spray progresses further downstream (beyond the 420 measurements from focused-beam radiography) the spray angle increases. This explains the 421 larger spray angle for shadowgraphy and tube-source radiography, because they both captured a 422 larger spray field of view. As the gas momentum flux ratio increases, the spray angle found from 423 the three methods are more similar because the physical extent of the near-field becomes smaller 
Second revision for submission to: International Journal of Multiphase Flow

424 and the three imaging methods capture the same physics in their different fields of view. This

425 shows that the spray edge at lower momentum flux ratios are not completely straight. Improved

426 measurements would have focused-beam measurements further downstream, to ensure the same

427 spray field for all measurement techniques. The most accurate value of the spray angle is found

428 through focused-beam radiography because of the high precision of the measurements. The angle

429 found from tube-source radiography is more accurate than shadowgraphy since the average map

430 of shadowgraphy shows the presence or not of liquid, rather than the amount of liquid. However,

431 the high correspondence between tube-source measurements and shadowgraphy show that the

432 probability map found from shadowgraphy could be used with acceptable accuracy for finding

433 the spray angle at high momentum flux ratios.

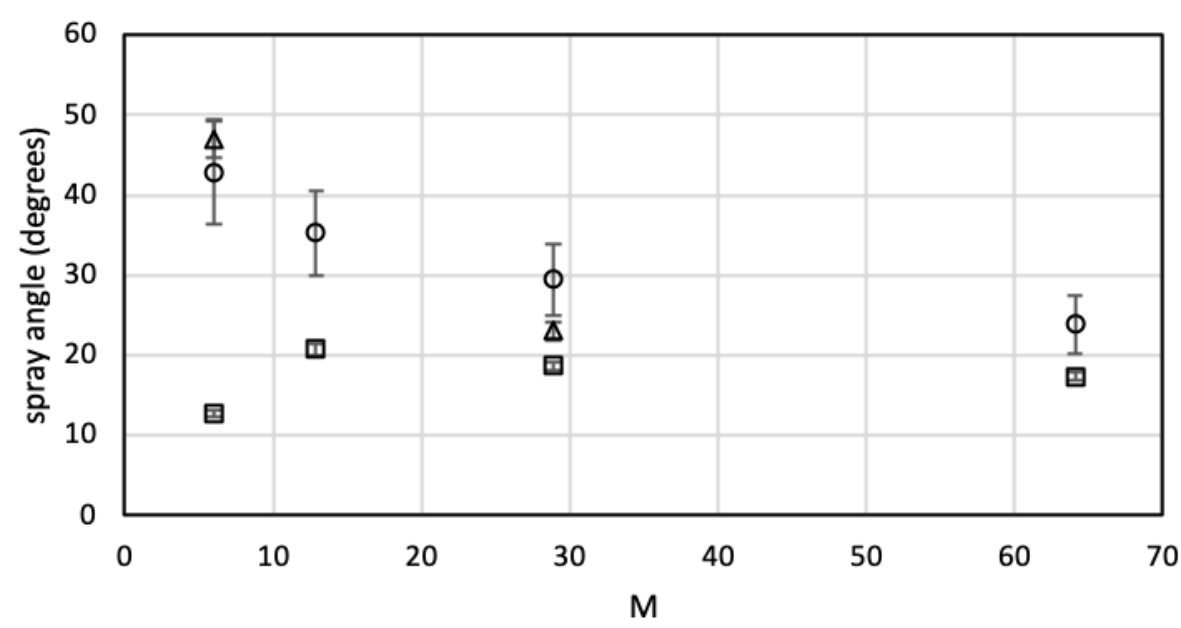

O back-illuminated $\quad \square$ focused-beam $\quad \Delta$ tube source

435 Figure 11: Comparison of spray angle for multiple testing techniques at varying momentum flux ratios, where the error bars represent the estimated experimental error. 
Second revision for submission to: International Journal of Multiphase Flow

\subsection{Intact Length Comparison}

439 The intact length $\left(\mathrm{L}_{\mathrm{b}}\right)$ of a spray is defined as the average axial length at which the liquid

440 remains attached to the nozzle. This attachment is either caused by a liquid core or ligaments that

441 remain connected to the liquid at the nozzle tip. The intact length for shadowgraphy $\left(\mathrm{L}_{b, \mathrm{SI}}\right)$ was

442 computed by measuring the intact length from a series of images using image processing to

443 determine the longitudinal extend of the liquid core on each instantaneous image. The lengths

444 were then averaged, as shown in Figure 12, for varying gas momentum flux ratios. Visual

445 inspection of the intact length from the image series showed minimal error from detached

446 ligaments and droplets that obscured the measurement, even in sprays with higher momentum

447 ratios where droplet clouds are present. For sprays with a denser cloud of droplets surrounding

448 the liquid core, it will often be necessary to estimate the intact length from other measurements,

449 such as X-ray radiography. The method for estimating the intact length is below. 
Second revision for submission to: International Journal of Multiphase Flow

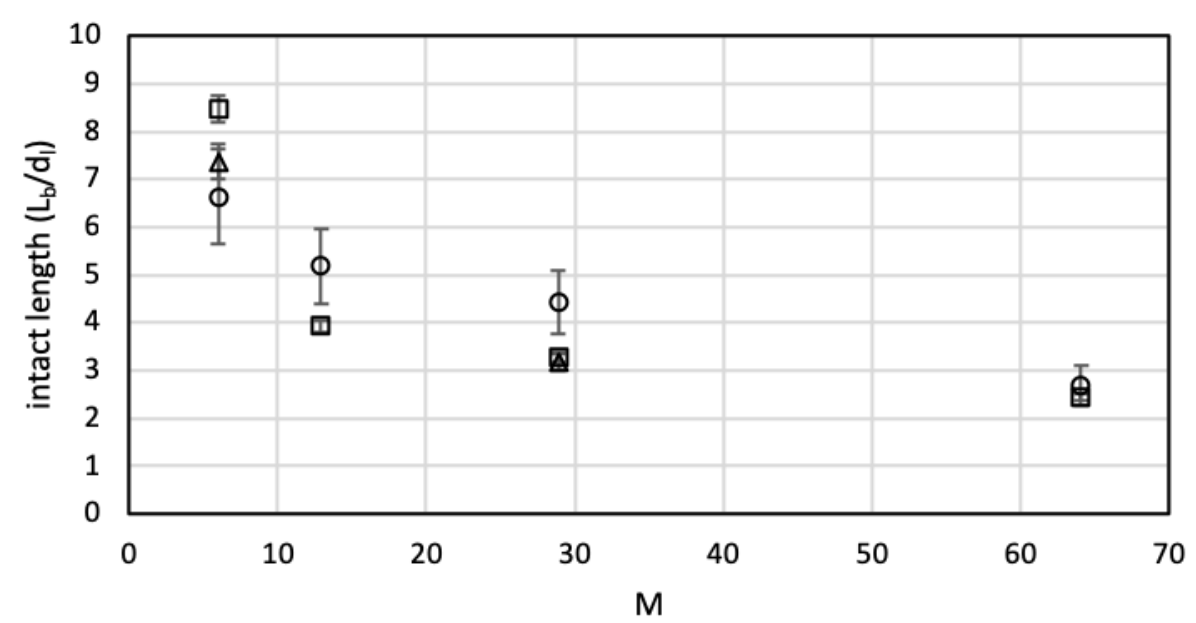

Oback-illuminated $\square$ focused-beam $\quad \Delta$ tube source

451 Figure 12: Comparison of intact length for multiple testing techniques at varying momentum flux ratios, where the error bars represent the estimated experimental error.

For measurements that use the EPL, the core length has been shown to correlate to the 455 distance where the average EPL along the centerline is $30 \%$ of the maximum EPL $\left(\mathrm{EPL}_{\max }\right)$ 456 along the centerline of the particular spray (Lightfoot et.al., 2015). It is important to note that the 457 core length and intact length are not the same measure and the core length does not have a 458 consistent definition throughout the literature. However, using the same technique as Lightfoot et 459 al. (2015), a ratio of EPL to EPL ${ }_{\max }$ was defined that provides a reasonable estimate of the intact 460 length. For focused-beam radiography, the ratio found that provides the most accurate intact 461 length is $\mathrm{L}_{\mathrm{b}, \mathrm{FB}}=0.02 * \mathrm{EPL}\left(\mathrm{x}_{0}\right)_{\max }$. The $\mathrm{L}_{\mathrm{b}, \mathrm{FB}}$ ratio was found by determining the EPL value along 462 the centerline, at the intersection of the intact length (as found from shadowgraphy). Because 463 focused-beam radiographs are point measurements, if the intact length location did not lie on a 464 point, the values between points were estimated using a linear fit between the two nearest axial 
Second revision for submission to: International Journal of Multiphase Flow

465 locations. A comparison of the results shows that a good estimate of the intact length was found 466 from focused-beam imaging, shown in Figure 12.

467 The same method was used to estimate the intact length from tube-source X-ray images.

468 The ratio of intensity along the centerline was calculated for $\left(\mathrm{I} / \mathrm{I}_{0}\right)$ as $20 \%$ where

$469 \mathrm{~L}_{\mathrm{b}, \mathrm{TS}}=0.20 * \mathrm{I}_{\max }\left(\mathrm{x}_{0}\right) / \mathrm{I}_{0}$, indicating that the threshold may be a function of the X-ray power and

470 spectrum. The resulting intact lengths from this method are shown in comparison to the more

471 direct measurements from shadowgraphy in Figure 12. The high correspondence between the

472 shadowgraphy and tube-source radiography intact lengths show that the estimate from tube-

473 source radiography was a reasonable estimate.

474 Phase-contrast images were not used in estimating the intact length because the field of

475 view was too small so the spray had to be imaged in sections. Thus, the core or attached

476 ligaments did not all fit into one imaging frame. Additionally, the differences in the projected

477 intensity between spray regions where the liquid core was intact and where it was broken into a

478 multitude of large liquid droplets made the detection of intact length uncertain. The intensity

479 difference could be magnified in future experiments by doping the liquid with a sensitizer,

480 similar to the KI that was added to the water for tube source X-ray imaging.

\section{4. Discussion}

Shadowgraphy required less time for data acquisition because the system was capable of

484 capturing a large portion of the flow field in a single set-up. Unlike X-ray images, shadowgraph

485 images do not show the internal dynamics of sprays or the initial bag and ligament formation, so

486 they can only be used where a binary image showing the outline of the spray will suffice. 
Second revision for submission to: International Journal of Multiphase Flow

487 Shadowgraphy is a great option for obtaining the core length of a spray and an excellent option

488 for initial testing or proof of concept testing to qualitatively assess the spray uniformity.

With tube-source radiography, it was not possible to capture all the same breakup

490 dynamics as with the synchrotron beam or shadowgraphy because a longer exposure was

491 required to account for the low intensity source. However, it was possible to capture the entire

492 spray region in the same image, which was not possible with synchrotron imaging. One of the

493 largest benefits of using a tube-source X-ray setup is the ease of access when compared to the

494 synchrotron source because it is possible to install a tube-source in a university or industrial lab 495 setting.

Synchrotron phase-contrast imaging works well for qualitative space- and time-resolved

497 analysis of the spray features. The images showed droplet formation, bubbles, ligaments, as well

498 as bag formation and breakup. An image time series (i.e., video) can also show complex breakup

499 events with internal air bubbles (Li et al., 2017). Quantitative measurements from white-beam

500 images are possible but were challenging in this study because of the small intensity differences

501 between the regions with and without liquid, and the inability to correlate objects across imaging

502 regions.

503 Focused-beam radiography yielded accurate EPL values for the near-field region of the

504 spray. They were also highly time-resolved and were used to find the equivalent path length

505 statistics. However, the line-of-sight measurements do not allow for spatial and temporal

506 information to be acquired at the same time unless the spray is highly repeatable and the data

507 acquisition system is phase-locked (which was not the case in this study). Focused-beam

508 measurements often require another experimental technique such as shadowgraphy or

509 synchrotron white-beam measurements to probe the spray in a complementary way. The 
Second revision for submission to: International Journal of Multiphase Flow

510 mechanisms of breakup can be made evident through imaging and then quantitative statistics

511 from the focused-beam measures can better quantify spray parameters.

\section{5. Conclusions}

514 Using focused-beam radiography, a Gaussian distribution of the EPL was found near the

515 exit plane. The Gaussian behavior continued to exist as the spray progressed downstream with

$516 \operatorname{EPL}(\mathrm{x})_{\max }$ decreasing and the spray width increasing. Scaling the spray based on the $\operatorname{EPL}(\mathrm{x})_{\max }$,

517 and the $2 \sigma$ width of the Gaussian fit as the spray edge, shows the EPL distributions collapsing

518 into a single curve, proving that they are self-similar.

519 An accurate measure of the spray angle was determined using focused-beam radiography

520 and tube-source radiography. The spray angle from shadowgraph imaging provided similar

521 results to those from focused-beam radiography and tube-source radiography at high gas

522 momentum flux ratios. However, focused-beam radiography showed a smaller spray angle at low

523 gas momentum flux ratios because the angle changes downstream and the spray region that was

524 required to get a reasonable estimate at these conditions was larger than the field of view used in

525 this study for focused-beam radiography. Although the spray angle from shadowgraphy came

526 from a binary distribution of the probability of liquid intercepting the light beam, rather than an

527 average EPL, the results show that it can provide a reasonable estimate of the spray angle.

528 The intact length was most accurately determined through shadowgraphy. For focused-

529 beam radiography, a threshold value of $2 \%$ of the EPL $\max$ along the centerline of the jet resulted

530 in a strong correlation with the results from shadowgraphy. The threshold value for tube-source

531 imaging that provided the most accurate intact length is $20 \%$ of the $\mathrm{I}_{\max }$ which also showed good

532 correlation to the intact length from shadowgraphy. 
Second revision for submission to: International Journal of Multiphase Flow

\section{Acknowledgments}

535 This work was sponsored by the Office of Naval Research (ONR) as part of the

536 Multidisciplinary University Research Initiatives (MURI) Program, under grant number

537 N00014-16-1-2617. The views and conclusions contained herein are those of the authors only

538 and should not be interpreted as representing those of ONR, the U.S. Navy or the

539 U.S. Government.

540 A portion of this work was performed at the 7-BM beamline of the Advanced Photon

541 Source, a U.S. Department of Energy (DOE) Office of Science User Facility operated for the

542 DOE Office of Science by Argonne National Laboratory under Contract No.

543 DE-AC02-06CH11357.

544 The tube source X-ray work was completed in the X-ray flow visualization facility at

545 Iowa State University, which was developed with support from the National Science Foundation

546 under award number CTS-021637 and Iowa State University.

\section{$548 \quad$ References}

549 Aggarwal, S. K. (1998). A review of spray ignition phenomena: present status and future

$550 \quad$ research. Progress in Energy and Combustion Science, 24(6), 565-600.

551 Berger, M. J., Hubbell, J. H., Seltzer, S. M., Chang, J., Coursey, J. S., Sukumar, R., Zucker, D.S.,

552 Olsen, K. (2010). XCOM: Photon Cross Section Database (version 1.5). [Online] Available:

553 http://physics.nist.gov/xcom [2019, May 1]. National Institute of Standards and Technology,

$554 \quad$ Gaithersburg, MD. 
Second revision for submission to: International Journal of Multiphase Flow

555 Castrejón-García, R., Castrejón-Pita, J. R., Martin, G. D., \& Hutchings, I. M. (2011). The

556 shadowgraph imaging technique and its modern application to fluid jets and drops. Revista

557 Mexicana de física, 57(3), 266-275.

558 Charalampous, G., Hadjiyiannis, C., \& Hardalupas, Y. (2016). Comparative measurement of the 559 breakup length of liquid jets in airblast atomisers using optical connectivity, electrical $560 \quad$ connectivity and shadowgraphy. Measurement, 89, 288-299.

561 Halls, B. R., Heindel, T. J., Kastengren, A. L., \& Meyer, T. R. (2014). Evaluation of X-ray 562 sources for quantitative two-and three-dimensional imaging of liquid mass distribution in 563 atomizing sprays. International Journal of Multiphase Flow, 59, 113-120.

564 Halls, B., Radke, C., Heindel, T., Lohry, W., Zhang, S., Meyer, T., \& Gord, J. (2013).

565 Characterization of three-dimensional dense spray visualization techniques. In 51st AIAA

566 Aerospace Sciences Meeting including the New Horizons Forum and Aerospace

$567 \quad$ Exposition (p. 477).

568 Heindel, T. J., Gray, J. N., \& Jensen, T. C., (2008). An X-ray system for visualizing fluid flows.

$569 \quad$ Flow Measurement and Instrumentation, 19(2), 67-78.

570 Heindel, T. J. (2018). X-ray imaging techniques to quantify spray characteristics in the near571 field. Atomization and Sprays, 28(11), 1029-1059.

572 Kastengren, A., Powell, C. F., Arms, D., Dufresne, E. M., Gibson, H., \& Wang, J. (2012). The 5737 BM beamline at the APS: A facility for time-resolved fluid dynamics measurements.

$574 \quad$ Journal of Synchrotron Radiation, 19(4), 654-657.

575 Kastengren, A. L., Powell, C. F., Riedel, T., Cheong, S. -K., Im, K. -S., Liu, X., Wanng, Y. J., \& 576 Wang, J. (2008). Nozzle geometry and injection duration effects on diesel sprays measured 577 by X-Ray radiography. Journal of Fluids Engineering, 130(4), 041301. 
Second revision for submission to: International Journal of Multiphase Flow

578 Lasheras, J. C., \& Hopfinger, E. J. (2000). Liquid jet instability and atomization in a coaxial gas 579 stream. Annual Review of Fluid Mechanics, 32(1), 275-308.

580 Lasheras, J. C., Villermaux, E., \& Hopfinger, E. J. (1998). Break-up and atomization of a round $581 \quad$ water jet by a high-speed annular air jet. Journal of Fluid Mechanics, 357, 351-379.

582 Law, C. K. (1982). Recent advances in droplet vaporization and combustion. Progress in Energy $583 \quad$ and Combustion Science, 8(3), 171-201.

584 Li, D., Bothell, J. K., Morgan, T. B., Heindel, T, J., Aliseda, A., Machicoane, N., \& Kastengren, 585 A. L., High-speed X-ray imaging of an airblast atomizer at the nozzle exit, $7^{\text {th }}$ Annual 586 Meeting of the American Physical Society Division of Fluid Dynamics, Denver, Colorado, 587 November 19-21, 2017. DOI: https://doi.org/10.1103/APS.DFD.2017.GFM.V0026.

588 Li, D., Bothell, J. K., Morgan, T. B., Heindel, T. J., Aliseda, A., Machicoane, N., \& Kastengren, 589 A. L., Quantitative analysis of an airblast atomizer near-field region using broadband and $590 \quad$ narrowband X-ray sources, ICLASS 2018, $14^{\text {th }}$ Triennial International Conference on Liquid $591 \quad$ Atomization and Spray Systems, Chicago, Illinois, July 22-26, 2018, Submission-ID: 141.

592 Li, D., Bothell, J. K., Morgan, T. B., Machicoane, N., Aliseda, A., Kastengren, A. L., \& Heindel, 593 T. J. (2019). Time-averaged spray analysis in the near-field region using broadband and 594 narrowband X-ray measurements. Atomization and Sprays, 29(4), 331-349.

595 Lightfoot, M. D., Schumaker, S. A., Danczyk, S. A., \& Kastengren, A. L. (2015). Core length 596 and spray width measurements in shear coaxial rocket injectors from X-ray radiography 597 Measurements (No. AFRL-RQ-ED-TP-2015-115). Air Force Research Lab, Edwards AFB, $598 \quad$ CA, Aerospace Systems Directorate.

599 Linne, M. (2013). Imaging in the optically dense regions of a spray: A review of developing $600 \quad$ techniques, Progress in Energy and Combustion Science, 39(5), 403-440. 
Second revision for submission to: International Journal of Multiphase Flow

Linne, M. A., Paciaroni, M., Berrocal, E., \& Sedarsky, D. (2009). Ballistic imaging of liquid breakup processes in dense sprays. Proceedings of the Combustion Institute, 32 II(2), 21472161.

Machicoane, N., Bothell, J. K., Li, D., Morgan, T. B., Heindel, T. J., Kastengren, A. L., \& Aliseda, A., (2019). Synchrotron radiography characterization of the liquid core dynamics in a canonical two-fluid coaxial atomizer, International Journal of Multiphase Flow, 115, 1-8.

Powell, C. F., Yue, Y., Poola, R., \& Wang, J. (2000). Time-resolved measurements of supersonic fuel sprays using synchrotron X-rays. Journal of Synchrotron Radiation, 7(6), 356-360.

Stevenin, C., Tomas, S., Vallet, A., Amielh, M., \& Anselmet, F. Shadowgraphy investigations of high speed water jet atomization into still air. ICLASS 2012, 12th Triennial International Conference on Liquid Atomization and Spray Systems. Heidelberg, Germany, September, 2012.

Westlye, F. R., Penney, K., Ivarsson, A., Pickett, L. M., Manin, J., \& Skeen, S. A. (2017). Diffuse back-illumination setup for high temporally resolved extinction imaging. Applied Optics, 56(17), 5028-5038.

Van Wissen, R. J., Schreel, K. R., \& Van Der Geld, C. W. (2005). Particle image velocimetry measurements of a steam-driven confined turbulent water jet. Journal of Fluid Mechanics, 530, 353-368.

Yue, Y., Powell, C. F., Poola, R., Wang, J. C., \& Schaller, J. K. (2001). Quantitative measurements of diesel fuel spray characteristics in the near-nozzle region using X-ray absorption. Atomization and Sprays, 11(4), 471-490. 